\title{
A Modified and Simplified Behavioral System Associated with Management Procedures for Assessing and Managing the Aggression Level of Free Roaming Dogs
}

\section{Amal H. Mostafa, Mohammed Y. Matoock, Нeba M. A. KhaliL*}

Veterinary Hygiene and Management Department, Faculty of Vet. Medicine, Cairo University, Giza, 12211, Egypt

\begin{abstract}
The current study implemented a modified behavioral evaluation associated with a management program for stray dogs. Eight adult native dogs were collected from Maadi district streets in Cairo. and brought to the clinic to assess their aggression level. They were exposed to a 10 behavioral test series, including friendly greeting, room behavior, leash manner, look test, sensitivity test, tag test, squeeze test, food behavior, toy behavior, and dog to dog behavior to measure the dog's initial reaction and subsequent recovery. Then they were housed in kennels and retested after being subjected to a management procedures for one week. Most of the dogs showed no aggression in the friendly greeting test and room behavior test, moderate response for a look test and tag test, while displayed high aggressive response during leash manner, sensitivity, squeeze, food behavior, toy behavior, and dog to dog behavior tests as well. Dogs aggressive responses were reduced in all previous tests following exposure to a good management program. In conclusion, our modified behavioral system with suitable management procedures was successful; in terms of timesaving, accuracy, and reliability in assessing and managing free roaming dog's aggressive level.
\end{abstract}

Keywords | Free roaming dogs, Aggression, SAFER, MATCH-UP-II, Management

Received | October 15, 2021; Accepted | November 27, 2021; Published | January 10, 2022

*Correspondence | Heba M. A. Khalil, Department of Veterinary Hygiene and Management, Faculty of Veterinary Medicine, Cairo University, Giza, 12211, Egypt; Email: heba.ali315@gmail.com, heba.ali@cu.edu.eg

Citation | Mostafa AH, Matoock MY, Khalil HMA (2022). A modified and simplified behavioral system associated with management procedures for assessing and managing the aggression level of free roaming dogs. Adv. Anim. Vet. Sci. 10(2): 369-376.

DOI | http://dx.doi.org/10.17582/journal.aavs/2022/10.2.369.376

ISSN (Online) | 2307-8316

\section{INTRODUCTION}

$\mathrm{C}$ anine aggression is a threatening behavior that involves a harmful act to either other dogs or human beings (Farhoody et al., 2018). It includes body language or threat displays such as a hard stare, growling, barking, snarling, lunging, snapping, and biting (Yang et al., 2021). It is regulated by various genetic, neurochemical, and hormonal factors (Col et al., 2016). There are many types of canine aggression, such as dominance aggression, sexual aggression, possessive aggression, pain-related aggression, and fear-related aggression, which is perhaps the most common form of aggression in dogs (Caffrey et al., 2019).

The global population of domestic dogs (Canisfamiliarise) is estimated to be 700 million, with around $75 \%$ free-roaming dogs (FRD) (Belsare and Vanak, 2020). Street dogs are FRD that are not confined to a yard or house (Smith et al., 2019). They are responsible for the transmission of a wide range of parasitic, bacterial, viral, protozoal, and fungal infections to humans (Özen et al., 2016; Warembourg et al., 2021). Also, they are responsible for dog bite injuries and road traffic accidents, making noise pollution, disturbing pedestrians and drivers, spreading garbage, and passing feces everywhere (Acharya and Dhakal, 2015).

Therefore, controlling FBD becomes a demand that could be achieved through implementing a reasonable management procedure (MPs). Dog management is the art of practicing proper procedures that ensure raising well-behaved dogs (Burch, 2020). Its goal is to prevent a problem before it starts by altering the environment or, to 
figure out a way to stop the dog from doing inappropriate behavior, teach it what to do instead (Protopopova and Gunter, 2017; Savalli et al., 2019). For example, the cause of fear-aggressive dogs is the lack of adequate dog exercise that is the root of the dog aggressive behavior (Rezac et al., 2017). Also, dog's health conditions like disease or pain may influence aggression (Mornement et al., 2015). Moreover, proper vaccination and treatment can prevent or eliminate dog suffering and unwanted behaviors (Stellato et al., 2021). Furthermore, providing dogs with balanced food at a specific time every day reduces food aggression and conflict due to decreased competition over food (Bray et al., 2021). Several attempts were made to assess the aggression of FRDs (Braem et al., 2017). Safety Assessment for Evaluating Rehoming program (SAFER) and MATCHUP II (which refers to marder animal rescue league test for canine homing using personality) assessments are the most commonly used programs for this purpose. SAFER is an aggression assessment tool designed by Emily Weiss (Weiss, 2002), it includes a seven-item assessment that could be completed in less than eight minutes utilizing an assessor and an observer, staff knowledgeable about dog behavior, and possessed excellent observation and safe animal handling skills. It is characterized by low cost to implement and shorter time to conduct associated with resenable accuracy (Zawistowski, 2010).

However, MATCH-UP II is an objective way to evaluate dog behavioral tendencies and personality because the dog's responses in each sub-test are described by observed behaviors, body postures, and movement. It consists of eleven sub-tests that take twenty minutes to complete (Dowling-Guyer et al., 2011). Therefore, the study aims to implement a modified evaluation characterized by accuracy than SAFER, reliability, and a shorter time than MATCHUP II amalgamated with a successful management system to reduce canine aggression.

\section{MATERIALS AND METHODS}

\section{ETHICAL CONSIDERATIONS}

This study complied with the ARRIVE guidelines (Percie du Sert et al., 2020). Furthermore, it was approved by the Veterinary Institutional Animal Care and Use Committee (Vet-IACUC) (Approval Number: VetCU12/10/2021/341) of Cairo University.

\section{Subjects}

Eight adult native dogs ( $>1$ year ), seven males and one female, mean age $2 \mathrm{Y}$ participate in the test. The subjects are recruited from the streets of Maadi district (Cairo, Egypt), and subjected to trap, neuter, Return, management program (TNRM). Based on the dog history from neighborhood residences, these dogs show aggression towards humans.
The test is applied twice, the first time in arrival and repeated following the management procedures.

\section{BEHAVIORAL APPROACH}

Subjects were tested in a visually separated, unfamiliar open-air area. The test series consisted of 10 tests in a fixed order and presented in Table 1, Figure 1. The reason for using a fixed order is to characterize the overall aggressive response of the dogs without risking injury to the dog or tester, starting with preparation tests. The duration of each test is about $60 \mathrm{sec}$; thus, the whole test series took about 10 min per dog. All tests were video recorded for later analysis.

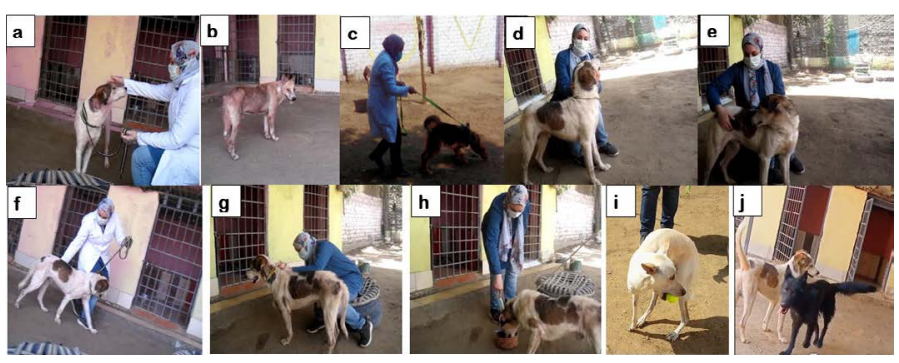

Figure 1: Representative images of behavioral assessments approach. A, Friendly greeting test; b, Room behavior test; c, Leash manner test; d, Look test; e, Sensitivity test; f, Tag test; g, Squeeze test; h, Food behavior test; i, Toy behavior test; $\mathrm{j}$, Dog to dog test.

\section{Management Procedures (MPs)}

Each dog was subjected to the following MPs.

\section{Housing}

Dogs are housed in individual kennels approximately $1.5 \mathrm{~m}^{2}$, with outside drain channels, a large fenced play yard, and attached to a fully equipped veterinary clinic. Blankets are used for bedding.

\section{FeEding}

Dogs are served daily with a mix of fresh and dry food meals consist of mixed vegetables, chicken or minced meat, bread, soup with 1 cup ( 8 ounces, 224 grams) of dry food (Royal $\mathrm{Canin}^{\mathrm{R}}$, France). They have access to water $24 \mathrm{~h}$ a day.

\section{EXERCISE}

Dogs are given access to the play yard for 1 hour a day for exercise and training, using rubber chew toys, squeak toys, cotton playing rope, and tennis balls.

\section{Physical EXamination}

Routine examination of vital parameters (heart rate, respiratory rate, body temperature, mucous membrane) was performed as well as skin condition. The movement of dogs was observed to indicate any deformities, ex: lameness. Blood samples were collected for further laboratory analysis. 
Table 1: Behavioral approach, including the tests and procedures used for FRDs assessment.

\begin{tabular}{|c|c|}
\hline Test & Procedures \\
\hline Friendly greeting & Approach the dog and strokes it gently on the head with your hand. \\
\hline Room behavior & Drop the leash and let the dog explores the surroundings for a couple of mins then call the dog over to come. \\
\hline Leach manner & Walk dog outside. Observe leash behavior \\
\hline $\begin{array}{l}\text { Look (threatening } \\
\text { approach) }\end{array}$ & $\begin{array}{l}\text { coax the dog into a position between the knees, facing the assessor lightly cup dog's lower jaw in both hands } \\
\text { and encourage the dog with soft direct eye contact. }\end{array}$ \\
\hline Sensitivity & $\begin{array}{l}\text { Coax the dog to stand perpendicular to the assessor, grasp with pressure slightly more than normal touch and } \\
\text { lift and twist handfuls of skin and fur in a kneading motion, starting at the neck, following an inch or two } \\
\text { outside the spinal column, working down the dog's body past the tail to the flank and back up again }\end{array}$ \\
\hline Tag & $\begin{array}{l}\text { Begin moving around the room with the dog, remembering to keep the leash loose. Then with the body } \\
\text { lowered by slanting sideways away from the dog and bending at the knees, tag the dog's rear flank with two } \\
\text { fingers and say "POW!" }\end{array}$ \\
\hline Squeeze & $\begin{array}{l}\text { Pick up foreleg lightly run hand down to paw. Using just finger pads, squeeze between the dog's toe pads. } \\
\text { Increase pressure on the skin between the } 2 \text { toes until the dog responds. }\end{array}$ \\
\hline Food behavior & $\begin{array}{l}\text { Place bowl containing a mixture of kibble and canned food on the floor and slide it within the dog's reach. } \\
\text { Allow the dog a few moments to begin eating and "own" the bowl. The assessor then approaches the dog } \\
\text { head-on saying, "Give me that food!" in a normal tone of voice. Places Assess a Hand in the bowl, moving the } \\
\text { bowl approximately one foot toward the assessor. }\end{array}$ \\
\hline Toy behavior & $\begin{array}{l}\text { Gently rolls a toy or a rawhide within the dog's reach. Give the dog time to engage in chewing toys or } \\
\text { rawhide. Approach from the front and say, "Give me that toy!" while reaching for rawhide. Note the response } \\
\text { to rawhide removal. }\end{array}$ \\
\hline $\begin{array}{l}\text { Dog to dog } \\
\text { behavior }\end{array}$ & $\begin{array}{l}\text { Bring the helper dog to the assessment area. Enter with the dog being assessed. } \\
\text { Observe dog's responses as he notices and approaches helper dog. }\end{array}$ \\
\hline \multicolumn{2}{|c|}{$\begin{array}{l}\text { Score 1: No aggression, Dog leans forward or jumps up to lick the assessor's face with tail wagging, ears back, eyes averted and have } \\
\text { a relaxed body posture, dog stands still and accepts the touch; Score 2: Dog repeatedly turns toward the assessor's hand, gently places } \\
\text { his open mouth over the assessor's hand without applying Pressure, licks hands, pulls out of assessor's hands, his tail is between his } \\
\text { legs; Score 3: body stiff, tail up, ear forward, Dog will not allow the assessor to conduct the assessment; Score 4: Dog barks at the } \\
\text { assessor, growling, snarling; Score 5: Dog tries to bite. }\end{array}$} \\
\hline
\end{tabular}

\section{VACCINATION AND TREATMENT}

Each dog was given rabies vaccination (SERVAC 1amp, S/C), 5-day treatment of antibiotics $\left(\right.$ Betamox $^{\mathrm{R}}$ LA $1 \mathrm{ml} / 10 \mathrm{kgbw}, \mathrm{I} / \mathrm{M}$ ), Ivermectin $1 \%$ (Nasromectin $1 \mathrm{ml} / 50 \mathrm{kgbw}, \mathrm{S} / \mathrm{C})$ for flea and tick control, and some internal parasites.

\section{Statistical AnAlysis}

Percentages and frequencies of the raw data are presented as well as a paired-samples t-test was conducted using SPSS (SPSS 24.0 software; SPSS Inc., Armonk, NY, USA) to compare the aggression level of FRDs at arrival and the aggression level after implementing a MPs. Histograms were drawn by Graph Pad Prism Version 8.00 for Windows (Graph Pad Software, San Diego, California, USA). All results were expressed as means \pm SEM, and the significance level was set at $P \leq 0.05$.

\section{RESULTS AND DISCUSSION}

\section{FriendLy GREeTING}

Before MPs, about 6 dogs showed no aggression in which the dog stands still and accepts the touch, with tail wagging, ears back, and has a relaxed body posture. However, about one dog pulls out of assessor's hands, with tail between his legs. Likewise, one dog growled at the assessor showing aggression and the test relatively took long duartion. After the MPs, all dogs showed significantly less aggression in the friendly greeting test associated with significantly shorter time in performing the test (Fig. 2a, b).

\section{ROOM BEHAVIOR}

Before MPs, about five dogs showed no aggression as they approach the assessor in a friendly manner with tail wagging. However, three dogs stayed away from the assessor. After the MPs, the aggression level significantly decreased accompanied with a markedly less time consumed during this test (Fig. 2c, d).

\section{LEASH MANNER}

Before MPs, three dogs pulled the leash lightly. One dog pulled the leash medium. However, four dogs grabbed the leash hard and tried to bite the assessor. After the MPs, the aggression level significantly decreased accompanied with a markedly less time consumed during this test (Fig. 2e, f).

\section{LOOK TEST}

Before MPs, four dogs displayed no aggression, allow the 
head to be held loosely in assessor's cupped hands. two dogs pull out of the assessor's hands each time without settling during three repetitions. One dog did not allow the assessor to conduct the assessment with body stiff. One dog showed aggression, freeze growled, and tried to bite. After the MPs, the aggression level decreased, however not significant and the test time was markedly reduced (Fig. $3 \mathrm{a}, \mathrm{b}$ ).
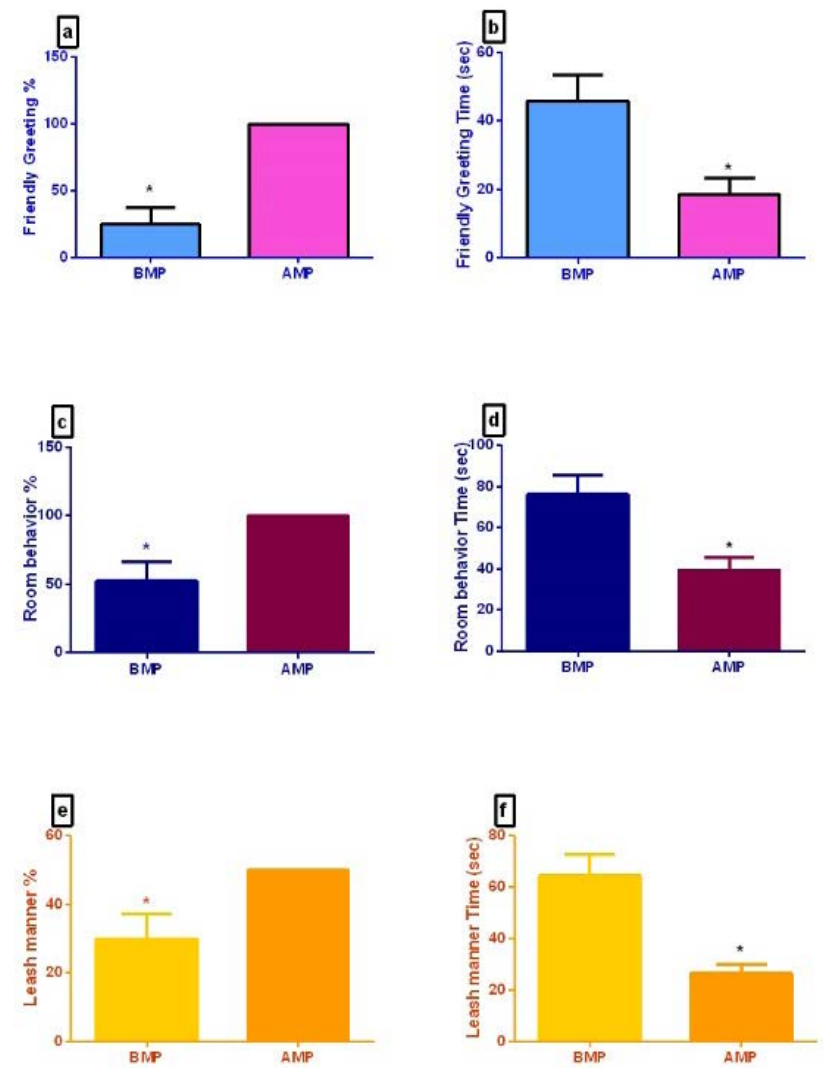

Figure 2: Effect of MPs on FRD's behavior and the duration spent in each test. a, b, Friendly greeting test \% and its time consumed; c, d, Room behavior test $\%$ and its time consumed; e, f, Leash manner test $\%$ and its time consumed. Data are presented as mean \pm S.E.M using paired T-test; SPSS, * means significant difference at 0.05 .

\section{SEnSITIVITY TEST}

Before MPs, four dogs showed no aggression, dogs stand and accept the touch, eyes are averted, and the tail is in a neutral position with relaxed body posture. One dog repeatedly turn toward the assessor's hand, with loose body and open mouth, mouth the hand, but do not apply pressure. One dog struggling to get away with tail up and ears forward. two dogs showed aggression by repeatedly turning toward the assessor's hand with a swift head movement. Dog muzzle punches the hand with snapping and growling. After the MPs, the aggression level decreased, however not significant and the test time was markedly reduced (Fig. 3 c, d).

\section{TAG TEST}

Before MPs, three dogs assume play position and joins the game. Dogs stand with their tails low and wagging and come toward the assessor in a friendly manner when the assessor ceases moving. Two dogs were fearful but unresponsive when touched and likely crouching. One dog repeatedly turn quickly away when touched, or repeatedly spin toward the touch, and repeatedly try to exit. Tail is tucked, mouth closed, body stiff. Two dogs showed aggression, and dogs stood their ground while not cornered and barked at the assessor with ears forward. After the MPs, the aggression level significantly decreased accompanied with a markedly less time consumed during this test (Fig. 3r, f).
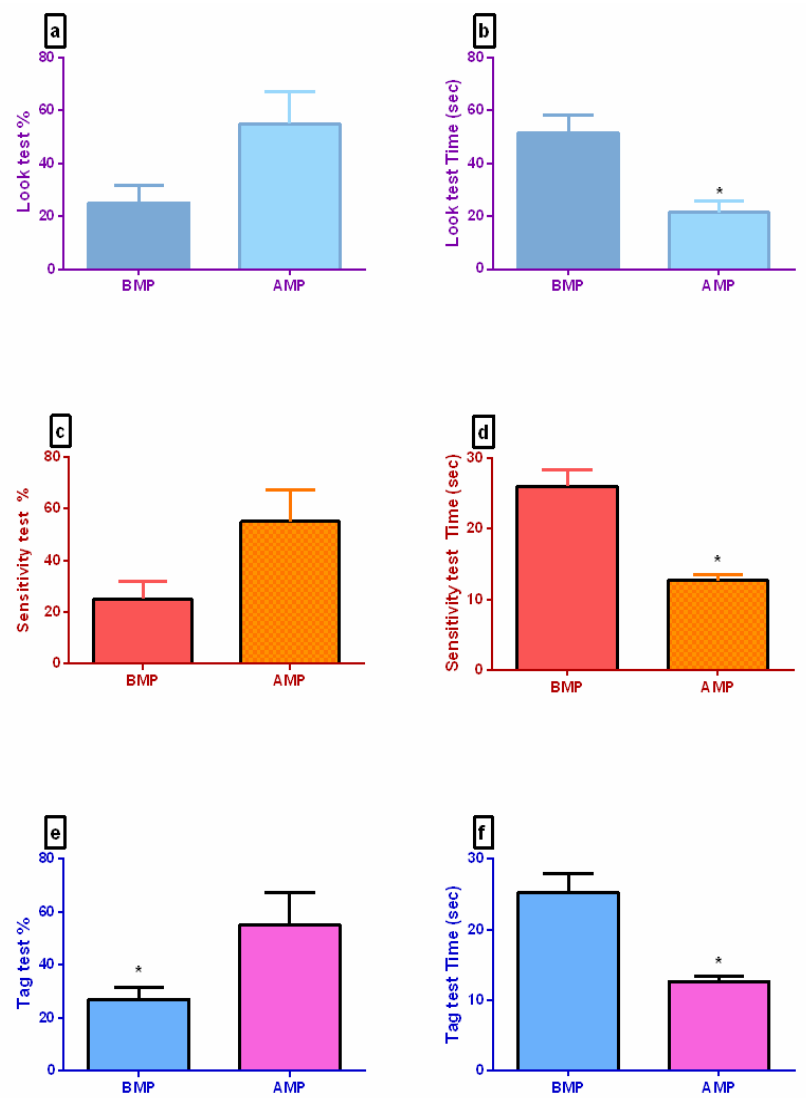

Figure 3: Effect of MPs on FRD's behavior and the duration spent in each test. a, b, Look test $\%$ and its time consumed; c, d, Sensitivity test $\%$ and its time consumed; e, $\mathrm{f}, \mathrm{Tag}$ test $\%$ and its time consumed. Data are presented as mean \pm S.E.M using paired T-test; SPSS, * means significant difference at 0.05 .

\section{SouEEZE TEST}

Before MPs, two dogs displayed no aggression. Dogs stand still and accept the touch, with tail wagging, ears back, eyes averted, and have a relaxed body. two dogs gently pull back the paw, dogs gently place an open mouth over the assessor's hand without applying pressure. One dog move their legs/body so that the assessor cannot hold the paw, with body stiff, tail up, and ears forward. Three dogs showed aggression in the form of growling. After the MPs, the aggression level decreased, however not significant and the test time was markedly reduced (Fig. 4 a, b). 

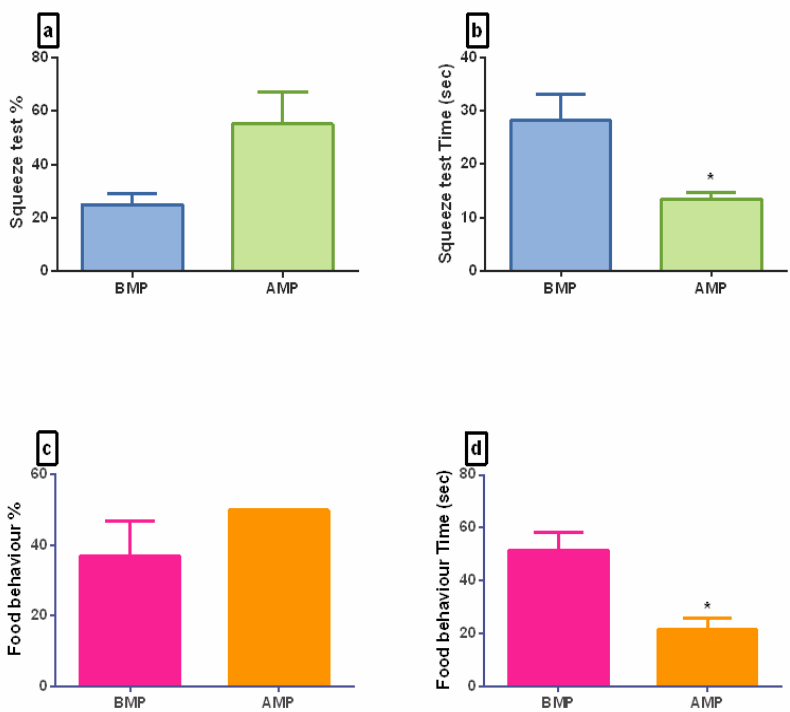

Figure 4: Effect of MPs on FRD's behavior and the duration spent in each test. a, b, Squeeze test \% and its time consumed; c, d, Food behavior test \% and its time consumed. Data are presented as mean \pm S.E.M using paired T-test; SPSS, * means significant difference at 0.05 .

\section{FOOD BEHAVIOR}

Before MPs, five dogs showed moderate aggression. Dogs follow the dish, gulp food, begin to eat faster and with bigger bites, tail between legs, ears are forward, the body is stiff. Dogs do not lift their head from the bowl when the hand is applied to their cheek. While two dogs growled. One dog try to bite. After the MPs, the aggression level decreased, however not significant and the test time was markedly reduced (Fig. 4c, d).

\section{Toy (RAWHIDE) BEHAVIOR}

Before MPs, only one dog took a toy away, keep a firm hold. The dog's body is between the assessor and the toy or rawhide. No growling or stiffness. Four dogs took toy/ rawhide away, keep a firm hold, the body is stiff. Three dogs freeze and growl, showing aggression. After the MPs, the aggression level significantly decreased accompanied with a markedly less time consumed during this test (Fig. 5a, b).

\section{DOG TO DOG BEHAVIOR}

Before MPs, three dogs approach the helper dog in play position, with mouth open. Two dogs do not approach the helper dog. Turn body away from other dog, or exit. Two dogs growled and barked. One dog charged the helper dog while attempting to bite. After the MPs, the aggression level decreased, however not significant and the test time was markedly reduced (Fig. 5c, d).

\section{TOTAL AGGRESSION LEVEL}

All behavioral assessment test were substantialy conducted in a shorter time, associated with a significant decrease in the total aggression score after MPs (Fig. 6 a, b).
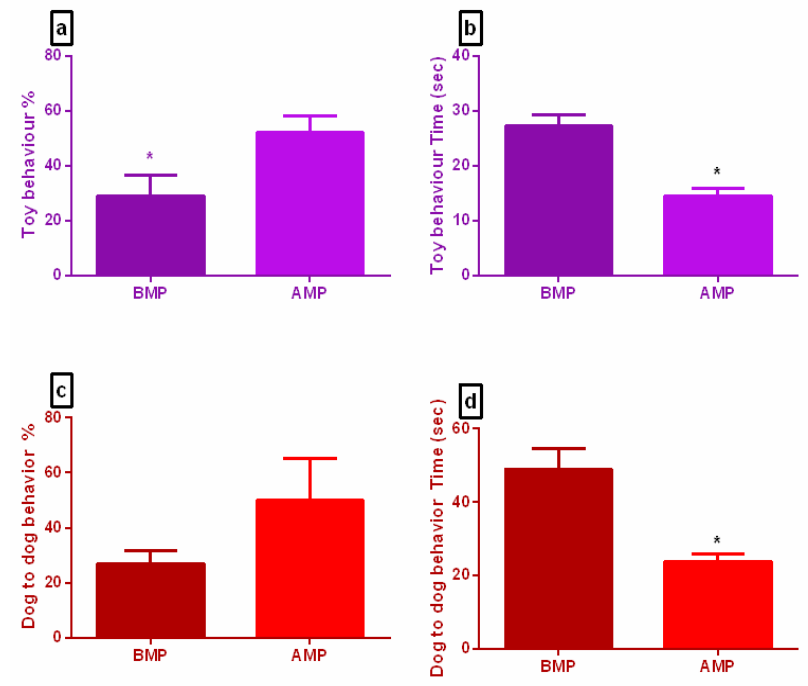

Figure 5: Effect of MPs on FRD's behavior and the duration spent in each test. a, b, Toy behavior test $\%$ and its time consumed; c, d, Dog to dog test \% and its time consumed. Data are presented as mean \pm S.E.M using paired T-test; SPSS, * means significant difference at 0.05 .
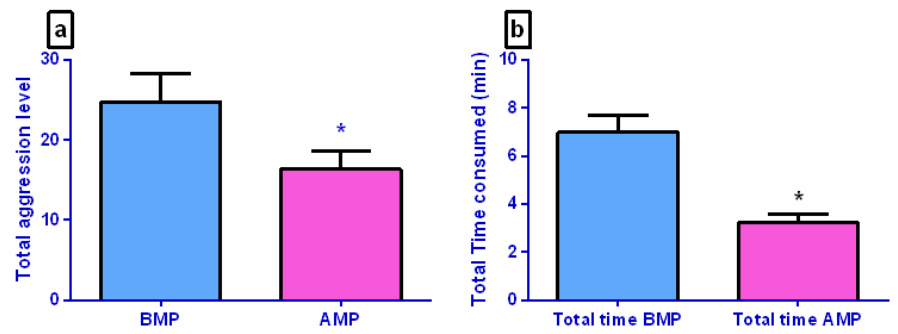

Figure 6: Effect of MPs on total aggression level and total time consumed during behavioral assessment of FRD. Data are presented as mean \pm S.E.M using paired T-test; SPSS, ${ }^{*}$ means significant difference at 0.05 .

The study's objective was to implement a modified behavioral assessment to evaluate FRD aggression level. Our modified test is easily administrated and can be conducted in a relatively short time which will make it suitable to detect and rehabilitate dogs with undesired behaviors as well as to improve dog health and welfare. The choice of the testing location is always critical, and a neutral testing environment is more suitable to avoid aggressive behaviors driven by protective or territorial aggression (Prato-Previde et al., 2018). In general, behavioral responses of dogs in human-dog interactions vary according to genetics, socialization with humans, and learning experience (Firnkes et al., 2017).

In our study, most dogs showed no aggression in the friendly greeting test. Dogs often regard the human hand as an alternative snout. The dog begins to sniff and consider the smooth touch as a signal sent in advance to express peaceful intentions and avoid conflict (Firnkes et al.,2017). This is driven by the fact that when they were away from 
their territory, they were more attentive, attempt to be calmer, seek social support, and were motivated to affiliate with the assessor (Klausz et al., 2014). Moreover, dogs can flexibly adjust their behavior to the attitude of the assessor (Bhattacharjee et al., 2018). However, dogs that showed an aggressive response in this test behaved aggressively in the majority of the subsequent tests. In particular, old dogs displayed less approaching and following behaviors toward the unknown human. As a result, this test can help in identify the persistently aggressive dogs.

In the room behavoir test, the dogs were busy exploring and investigating the unfamiliar area, they were curious, nondefensive, and expressed positive emotion to the assessor. The leash manner test is a good indicator of dominant and submissive dogs. Most of the dogs refused to put the leash on and showed aggression because they are not used to the leash and felt it a threat, the attempt of dominance by the tester, and tries to defend themselves (Shih et al., 2021).

In addition, the look test is a simple, straightforward test to administer and a good predictor of dog aggression, however, it is not easy to control, and since it was always the first test item, we need to start with the previous tests to increase control of dog response and ensure safe conditions for the assessor and the dog. The test suggested that human staring with specific body posture elicits fear and aggression in dogs as they translated it as a threatening approach, and consequently did not allow the assessor to conduct the test, and showed an aggressive response (Klausz et al., 2014). Other dogs looked away and pulled out of the assessors hand. Such signals are often considered a stress or anxiety indicators and seem to be used to reduce aggression. Another test is the sensitivity test that considered an accurate predictor of high-energy dogs as the dogs who did not stay still to accept the touch were rated tenser than other dogs (González-Martínez et al., 2019). The squeeze test and tag test are also reliable measures of submission in dogs as the dogs that accepted the touch are rated as a submissive dog (Chastain and Vellios, 2017).

Throughout the food behavior test, all dogs showed different degrees of aggression in stiffening, gulping, growling, freezing, and biting a fake hand during the assessment. It is well known that no one should take food away from the dog. Food aggression originates from instinct reaction to a threat (Mohan-Gibbons et al., 2018). Early domesticated dogs ate anything they could find, and resource competition was impacted by genetics, the individual's background, and the amount or the varieties of the available food. Despite domestication, these ritualized guarding behaviors continue to exist in dogs (MohanGibbons et al., 2012). It is considered necessary behavior in the wild because dogs protect their food from humans and other animals. The toy behavior correlated highly with possession aggression (Jacobs et al., 2018). Most dogs hold the toy or rawhide and refuse to drop it with body stiff and growling. It could be an indicator of overall stress levels, lack of enrichment, or exercise (Bálint et al., 2017).

Also, dog to dog test is distinct, it predicts dog aggression once conducted. A dog that rushes up to the helper dog with a tail high is more likely to exhibit aggressive behavior later during training procedures. During dogon-dog aggression, visual behavioral signals like lip lick, head turn, showing teeth, growling may indicate a direct threat (Montrose et al., 2020). A dog bite is motivated by predatory aggression or a lack of social exposure in early life (Schilder et al., 2019). Results from our study suggested that implementing a management program can result in avoiding triggers that elicit aggression in the FRDs. After a week of reasonable MPss, at least half of the dogs no longer exhibited any form of aggression. Proper housing provides each dog with its own space where it feels secure, with a quiet place for food and water and comfortable bedding; as a result, FRD avoids conflict and minimizes territorial aggression. Serving food at a specific time and adequate amount every day also reduces food aggression in FRD and becomes more controlled. They learned to sit and wait before lowering the food bowl due to possible training using treats, generally less stress, more daily interaction with humans, and less competition. In addition, providing proper exercises, daily walks, and playing games reduce aggression levels in FRD. This is in agreement with Kis et al. (2014) who confirmed that removing energy from the body leads to accessible communication with the mind.

In conclusion, In our study, we implemented a new modified system that succeeded in being more time effective and more accurate incorporated with a management system that consequently improved the behavior of FRD as they were more friendly after returning to their habitat. The newly modified system and the management protocol could be applied to many shelters, humane societies, and animal rescue organizations.

\section{NOVELTY STATEMENT}

A new modified behavioral system associated with management procedures (MP) was implemented to augment the behavior of free roaming-dogs (FRD).

\section{AUTHOR'S CONTRIBUTION}

Mohammed Y. Matoock and Heba M. A. Khalil: conceptualization, experimental design, supervising the work, analysis of data, and writing manuscript. Amal H. Mostafa: data collection, behavioral assessment, and writing manuscript. 


\section{CONFLICT OF INTEREST}

The authors have declared no conflict of interest.

\section{REFERENCES}

Acharya,M. and Dhakal, S.,2015. Survey on street dog population in Pokhara valley of Nepal. Bangladesh J. Vet. Med., 13(1): 65-70. https://doi.org/10.3329/bjvm.v13i1.23722

Bálint, A., Rieger, G., Miklósi, Á. and Pongrácz, P., 2017. Assessment of owner-directed aggressive behavioral tendencies of dogs in situations of possession and manipulation. R. Soc. Open Sci., 4(10): 171040. https://doi. org/10.1098/rsos.171040

Belsare, A. and Vanak, A.T., 2020. Modelling the challenges of managing free-ranging dog populations. Sci. Rep., 10(1): 1-12. https://doi.org/10.1038/s41598-020-75828-6

Bhattacharjee, D., Sau, S., and Bhadra, A., 2018. Free ranging dogs understand human intentions and adjust their behavioral responses accordingly. Front. Ecol. Evol., 6: 232. https://doi.org/10.3389/fevo.2018.00232

Braem, M., Asher, L., Furrer, S., Lechner, I., Würbel, H., and Melotti,L., 2017. Development of the "highly sensitive dog" questionnaire to evaluate the personality dimension "sensory processing sensitivity" in dogs. PLoS One, 12: e0177616. https://doi.org/10.1371/journal.pone.0177616

Bray, E.E., Otto, C.M., Udell, M.A.R., Hall, N.J., Johnston, A.M., and MacLean, E.L., 2021. Enhancing the Selection and Performance of Working Dogs. Front. Vet. Sci., 8: 430. https://doi.org/10.3389/fvets.2021.644431

Burch, M.R., 2020. Assessment of canine temperament: Predictive or prescriptive? Int.J. Comp. Psychol., 33. https:// doi.org/10.46867/ijcp.2020.33.01.01

Caffrey,N., Rock, M., Schmidtz, O.,Anderson, D., Parkinson, M., and Checkley, S.L., 2019. Insights about the epidemiology of $\operatorname{dog}$ bites in a canadian city using a dog aggression scale and administrative data. Animals, 9: 324. https://doi. org/10.3390/ani9060324

Chastain, C.B., and Vellios, L., 2017. Animal handling and physical restraint. CRC Press, Boca Raton. https://doi. org/10.1201/9781315153315

Col, R., Day, C., and Phillips, C.J.C., 2016. An epidemiological analysis of dog behavior problems presented to an Australian behavior clinic, with associated risk factors. J. Vet. Behav. Clin. Appl. Res., 15: 1-11. https://doi.org/10.1016/j. jveb.2016.07.001

Dowling-Guyer S, Marder A, D’Arpino S (2011). Behavioral traits detected in shelter dogs by a behavior evaluation. Appl. Anim. Behav. Sci. 130, 107-114. https://doi.org/10.1016/j. applanim.2010.12.004

Farhoody, P., Mallawaarachchi, I., Tarwater, P.M., Serpell, J.A., Duffy, D.L., and Zink, C., 2018. Aggression toward familiar people, strangers, and conspecifics in gonadectomized and intact dogs. Front. Vet. Sci., 5: 18. https://doi.org/10.3389/ fvets.2018.00018

Firnkes, A., Bartels, A., Bidoli, E., and Erhard, M., 2017. Appeasement signals used by dogs during dog-human communication. J. Vet. Behav., 19: 35-44. https://doi. org/10.1016/j.jveb.2016.12.012

González-Martínez, Á., Martínez, M.F., Rosado, B., Luño, I., Santamarina, G., Suárez, M.L., Camino, F., de la Cruz, L.F., and Diéguez, F.J., 2019. Association between puppy classes and adulthood behavior of the dog. J. Vet. Behav., 32: 36-41. https://doi.org/10.1016/j.jveb.2019.04.011

Jacobs, J.A., Coe, J.B., Widowski, T.M., Pearl, D.L., and Niel, L., 2018. Defining and clarifying the terms canine possessive aggression and resource guarding: A study of expert opinion. Front. Vet. Sci., 5: 115. https://doi.org/10.3389/ fvets.2018.00115

Kis, A., Klausz, B., Persa, E., Miklósi, Á., and Gácsi, M., 2014. Timing and presence of an attachment person affect sensitivity of aggression tests in shelter dogs. Vet. Rec., 174: 196-196. https://doi.org/10.1136/vr.101955

Klausz, B., Kis, A., Persa, E., Miklósi, A., and Gácsi, M., 2014. A quick assessment tool for human-directed aggression in pet dogs. Aggress. Behav., 40: 178-188. https://doi. org/10.1002/ab.21501

Mohan-Gibbons, H., Dolan, E.D., Reid, P., Slater, M.R., Mulligan, H., and Weiss, E., 2018. The impact of excluding food guarding from a standardized behavioral canine assessment in animal shelters. Animals, 8: 27. https://doi. org/10.3390/ani8020027

Mohan-Gibbons, H., Weiss, E., and Slater, M., 2012.Preliminary investigation of food guarding behavior in shelter dogs in the United States. Anim. Open Access J., MDPI 2: 331346. https://doi.org/10.3390/ani2030331

Montrose, V.T., Squibb, K., Hazel, S., Kogan, L.R., and Oxley, J.A., 2020. Dog bites dog: The use of news media articles to investigate dog-on-dog aggression. J. Vet. Behav., 40: 7-15. https://doi.org/10.1016/j.jveb.2020.08.002

Mornement, K.M., Coleman, G.J., Toukhsati, S.R., and Bennett, P.C., 2015. Evaluation of the predictive validity of the Behavioral Assessment for Re-homing K9's (B.A.R.K.) protocol and owner satisfaction with adopted dogs. Appl. Anim. Behav. Sci. Compl, pp. 35-42. https://doi. org/10.1016/j.applanim.2015.03.013

Özen, D., Böhning, D., and Gurcan, S., 2016. Estimation of stray dog and cat populations in metropolitan Ankara, Turkey. Turk. J. Vet. Anim. Sci., 40: 7-12. https://doi.org/10.3906/ vet-1505-70

Percie du Sert, N., Hurst, V., Ahluwalia, A., Alam, S., Avey, M.T., Baker, M., Browne, W.J., Clark, A., Cuthill, I.C., Dirnagl, U., Emerson, M., Garner, P., Holgate, S.T., Howells, D.W., Karp, N.A., Lazic, S.E., Lidster, K., MacCallum, C.J., Macleod, M., Pearl, E.J., Petersen, O.H., Rawle, F., Reynolds, P., Rooney, K., Sena, E.S., Silberberg, S.D., Steckler, T., and Würbel, H., 2020. The ARRIVE guidelines 2.0: Updated guidelines for reporting animal research*. J. Cereb. Blood Flow Metab., 40: 1769-1777. https://doi. org/10.1177/0271678X20943823

Prato-Previde, E., Nicotra, V., Pelosi, A., and Valsecchi, P., 2018. Pet dogs' behavior when the owner and an unfamiliar person attend to a faux rival. PLoS One, 13: e0194577. https://doi. org/10.1371/journal.pone. 0194577

Protopopova, A., and Gunter, L., 2017. Adoption and relinquishment interventions at the animal shelter: A review. Anim. Welf., 26: 35-48. https://doi. org/10.7120/09627286.26.1.035

Rezac, P., Koru, E., Havlicek, Z., and Pospisilova, D., 2017. Factors affecting dog jumping on people. Appl. Anim. Behav. Sci., 197: 40-44. https://doi.org/10.1016/j. applanim.2017.09.008

Savalli, C., Albuquerque, N., Vasconcellos, A.S., Ramos, D., de Mello, F.T., and Mills, D.S., 2019. Assessment of emotional predisposition in dogs using PANAS (Positive and Negative Activation Scale) and associated relationships in a sample 
of dogs from Brazil. Sci. Rep., 9: 18386. https://doi. org/10.1038/s41598-019-54645-6

Schilder, M.B.H., van der Borg, J.A.M., and Vinke, C.M., 2019. Intraspecific killing in dogs: Predation behavior or aggression? A study of aggressors, victims, possible causes, and motivations. J. Vet. Behav., 34: 52-59. https://doi. org/10.1016/j.jveb.2019.08.002

Shih, H.-Y., Paterson, M.B.A., Georgiou, F., Mitchell, L., Pachana, N.A., and Phillips, C.J.C., 2021. Two ends of the leash: Relations between personality of shelter volunteers and on-leash walking behavior with shelter dogs. Front. Psychol., 12: 1236. https://doi.org/10.3389/fpsyg.2021.619715

Smith, L.M., Hartmann, S., Munteanu, A.M., Dalla Villa, P., Quinnell, R.J., and Collins, L.M., 2019. The effectiveness of dog population management: A systematic review. Anim. Open Access J., MDPI 9, 1020. https://doi.org/10.3390/ ani9121020

Stellato, A.C., Flint, H.E., Dewey, C.E., Widowski, T.M., and Niel, L., 2021. Risk-factors associated with veterinaryrelated fear and aggression in owned domestic dogs. Appl. Anim. Behav. Sci., 241: 105374. https://doi.org/10.1016/j. applanim.2021.105374

Warembourg, C., Wera, E., Odoch, T., Bulu, P.M., BergerGonzález, M., Alvarez, D., Abakar, M.F., Maximiano Sousa, F., Cunha Silva, L., Alobo, G., Bal, V.D., López Hernandez, A.L., Madaye, E., Meo, M.S., Naminou, A., Roquel, P., Hartnack, S., and Dürr, S., 2021. Comparative study of freeroaming domestic dog management and roaming behavior across four countries: Chad, Guatemala, Indonesia, and Uganda. Front. Vet. Sci., 8: 96. https://doi.org/10.3389/ fvets.2021.617900

Weiss, E., 2002. Selecting shelter dogs for service dog training. J. Appl. Anim. Welf. Sci., 5: 43-62. https://doi.org/10.1207/ S15327604JAWS0501_4

Yang, J., Langford, F., and Kiddie, J., 2021. Risk factors for aggressive behavior in domestic dogs (Canis familiaris), as reported by owners in mainland China. Appl. Anim. Behav. Sci., 234: 105211. https://doi.org/10.1016/j. applanim.2020.105211

Zawistowski, S., 2010. The American society for the prevention of cruelty to animals (ASPCA). Encycl. Anim. Rights Anim. Welf., 1: 13-16. 